\title{
Chromosome 9p21.3 is associated with early-onset coronary heart disease in the Irish population
}

\author{
Weihua Meng ${ }^{\mathrm{a}}$, Anne E. Hughes ${ }^{\mathrm{a}}$, Chris C. Patterson ${ }^{\mathrm{a}}$, Christine Belton ${ }^{\mathrm{a}}$, Frank Kee ${ }^{\mathrm{a}}$ and \\ Pascal P. McKeown ${ }^{\mathrm{a}, \mathrm{b}, *}$ \\ ${ }^{a}$ Centre for Clinical and Population Sciences, Queen's University Belfast, Institute of Clinical Science, Grosvenor \\ Road, Belfast, Northern Ireland, UK \\ ${ }^{\mathrm{b}}$ Regional Medical Cardiology Centre, Royal Victoria Hospital, Grosvenor Road, Belfast, Northern Ireland, UK
}

\begin{abstract}
Coronary heart disease (CHD) remains a leading cause of death across the world. A region on chromosome 9p21.3 has been recently reported to be associated with CHD. We evaluated 3 SNPs and 3 common haplotypes in the 9p21.3 region in 1494 individuals from 580 Irish families, where at least 1 member had early-onset (males $\leqslant 55 \mathrm{yr}$, females $\leqslant 60 \mathrm{yr}$ ) CHD. Genotypes were determined by multiplex SNaPshot technology. Using the combined TDT/S-TDT test, the 3 single nucleotide polymorphisms (SNP), rs10757274, rs2383206 and rs1333049, were strongly associated with early-onset CHD $\left(p=2.7 \times 10^{-6}\right.$, $2.7 \times 10^{-6}, 3.8 \times 10^{-7}$, respectively). Analysis of haplotypes by the TRANSMIT program also showed that the GGC haplotype was associated with early-onset CHD $\left(p=7.9 \times 10^{-7}\right)$. In conclusion, using a family-based approach in the Irish population, we have confirmed previous reports of association between a region on chromosome 9p21.3 and early-onset CHD.
\end{abstract}

Keywords: Coronary heart disease, chromosome 9p21.3, genetics

\section{Introduction}

Coronary heart disease (CHD) is a major global health problem. Whilst traditional risk factors play a major role in the development of the disease, there is clear evidence that genetic factors are also important $[1$, 2]. However, over the years, despite intensive efforts, there has been a failure to replicate genetic associations across populations [3]. Recently, using a genomewide association study approach, several independent research groups have identified chromosomal regions which are associated with CHD; in particular, a small region spanning $58 \mathrm{~kb}$ on chromosome $9 \mathrm{p} 21$ has consis-

* Corresponding author: Dr. Pascal P. McKeown, Centre for Clinical and Population Sciences, Queen's University Belfast, Institute of Clinical Science, Grosvenor Road, Belfast, BT12 6BJ, Northern Ireland, UK. Tel.: +44 289063 4825; Fax: +44 289031 2907; E-mail: p.p.mckeown@qub.ac.uk. tently been reported to be very significantly associated with CHD [4-7].

In our study, we have investigated this region, using an Irish family based resource, where the probands had early-onset CHD.

\section{Materials and methods}

\subsection{Study subjects}

The family samples used in this study have been described in detail elsewhere [8,9]. From the period of August 1999 to October 2004 we recruited 1494 individuals from 580 families. All subjects were Caucasian whose 4 grandparents were born in Ireland. Each family had at least 1 member affected with early-onset CHD (disease onset $\leqslant 55$ years for males and $\leqslant 60$ years for females) and at least 1 unaffected sibling and / or both 
Table 1

Family structures of 1494 subjects in 580 families

\begin{tabular}{lcc}
\hline & $\begin{array}{c}\text { Number of } \\
\text { families }\end{array}$ & $\begin{array}{c}\text { Number of } \\
\text { individuals }\end{array}$ \\
\hline Proband+ parents + 0 sibling & 48 & 144 \\
Proband + parents + 1 sibling & 9 & 36 \\
Proband+ parents + 2 sibling & 7 & 35 \\
Proband +1 sibling & 337 & 674 \\
Proband +2 sibling & 128 & 384 \\
Proband +3 sibling & 39 & 156 \\
Proband+4 sibling & 8 & 40 \\
Proband+5 sibling & 3 & 18 \\
Proband+6 sibling & 1 & 7 \\
Total & 580 & 1494 \\
\hline
\end{tabular}

parents surviving. CHD was defined as the presence of 1 or more of the following features: (1) a history of acute myocardial infarction (MI) (as defined by WHO criteria); (2) a history of unstable angina (typical chest pain with dynamic ECG changes or minor elevations in cardiac markers); (3) coronary artery disease angiographically ( $\geqslant 70 \%$ luminal stenosis).

Unaffected siblings were required to: (1) be older than the affected sibling was at the onset of CHD; (2) have no symptoms of angina or possible MI by WHO questionnaire assessments [10]; (3) have no history of CHD diagnosed by a doctor; and (4) have a resting 12 lead ECG record showing no evidence of ischaemia or previous MI [11]. The study was approved by the Research Ethics Committee of Queen's University Belfast and informed consent was obtained from all subjects.

\subsection{Genotyping}

Three single nucleotide polymorphisms (SNP) (rs10 757274, rs2383206, rs1333049) were chosen for study, based on previous publications $[4,6]$. Genotypes were determined using multiplex SNaPshot technology, an ABI fluorescence-based assay allelic discrimination method (Applied Biosystems, USA). Each gel image was read by two independent observers unaware of the subject's disease status. GeneMarker V1.6 (Softgenetics, USA) was used to determine each allele.

\subsection{Statistical analysis}

The combined TDT/S-TDT test $[12,13]$ was used to assess the presence of association between the 3 SNPs and early-onset CHD by testing for unequal transmission of an allele from parents to affected offspring or unequal sharing of an allele within disease-discordant sibships. The combined TDT/S-TDT combines the TDT with the sibling TDT (S-TDT). Trios are informa- tive for the TDT at a given locus if there is an affected child and at least one parent is heterozygous. Sib pairs are informative for the S-TDT if there is at least one affected and one unaffected sibling with different genotypes. TRANSMIT was used to assess association using haplotype transmissions to affected offspring in the presence of uncertainty in haplotype assignment. The program makes use of parental genotypes (if available) as well as genotypes from siblings [14,15]. Only results for common haplotypes (estimated frequency $>1 \%$ ) are presented because of the unreliability of the chi-squared test for rare haplotypes.

\section{Results}

A total of 1494 individuals from 580 families were included (800 discordant sib-pairs and 64 parent-child trios). The family structures are summarized in Table 1. There are more male probands and more female siblings. With regard to traditional risk factors, the prevalence of smoking and diabetes mellitus is higher in the probands; blood pressure and cholesterol levels were lower in the probands, which may be related to therapeutic intervention (Table 2). Each SNP was strongly associated with early-onset CHD ( $p=2.7 \times 10^{-6}$, $2.7 \times 10^{-6}, 3.8 \times 10^{-7}$, respectively) (Table 3 ). There were over 300 informative families for each of the 3 SNPs. The haplotype analysis is shown in Table 4 . The GGC haplotype was associated with early-onset CHD $\left(p=7.9 \times 10^{-7}\right)$. The SNP genotype frequencies of the probands are summarized in Table 5 .

\section{Discussion}

Until recently, elucidation of the genetic basis of CHD has been dogged by non-replication of results [3]. The availability of modern genotyping technologies has facilitated the use of genomewide association studies using large, well-characterized case-control studies. These studies have consistently reported a strong association between CHD and a region on chromosome 9p21.3 [4-7]. In the study by Helgadottir and colleagues, about $21 \%$ of individuals were homozygous for the risk allele of rs 10757278 , with a corresponding odds ratio for development of MI of over 2.0 for earlyonset cases [5]. At present, the responsible gene in this region has not been identified. Sequencing of the 2 closest genes (tumour suppressor genes, CDKN2B and $\mathrm{CDKN} 2 \mathrm{~A}$, which play a role in regulating cell prolif- 
Table 2

Risk factors in probands with premature onset CHD and their unaffected siblings

\begin{tabular}{lll}
\hline Risk factor & $\begin{array}{l}\text { Probands } \\
(n=580)\end{array}$ & $\begin{array}{l}\text { Unaffected } \\
\text { Siblings }(n=758)\end{array}$ \\
\hline Age (yr); mean (SD) ** & $51.3(8.9)$ & $55.9(7.9)$ \\
Male; $\mathrm{n}(\%) * *$ & $467(80.5 \%)$ & $338(44.6 \%)$ \\
Ever smoker; $\mathrm{n}(\%) * *$ & $464(80.0 \%)$ & $432(57.0 \%)$ \\
Current smoker; $\mathrm{n}(\%) *$ & $215(37.1 \%)$ & $221(29.2 \%)$ \\
Hypertension treatment; $\mathrm{n}(\%)$ & $148(25.5 \%)$ & $170(22.4 \%)$ \\
SBP $\geqslant 140$ mmHg; $(\%) * *$ & $63(10.9 \%)$ & $337(44.5 \%)$ \\
DBP $\geqslant 95$ mmHg; $(\%) * *$ & $11(1.9 \%)$ & $94(12.4 \%)$ \\
Total hypertension; $\mathrm{n}(\%) * *$ & $179(30.9 \%)$ & $405(53.4 \%)$ \\
Diabetes diagnosed; $\mathrm{n}(\%) *$ & $53(9.1 \%)$ & $39(5.1 \%)$ \\
Total cholesterol (mmol/l); mean & $4.9(1.1)$ & $5.8(1.0)$ \\
$(\mathrm{SD}) * *$ & & \\
\hline$* p<0.01, * * p<0.001$. & & \\
SD - standard deviation, SBP - systolic blood pressure, DBP - diastolic blood \\
pressure.
\end{tabular}

Table 3

Association tests between 3 SNPs and premature heart disease performed using the Transmission Disequilibrium Test/Sibling Transmission Disequilibrium Test (TDT/S-TDT)

\begin{tabular}{lccccrc}
\hline SNP name & Allele & $\begin{array}{c}\text { Number of } \\
\text { informative families }\end{array}$ & Observed W* & Expected & Variance & p-value \\
\hline rs10757274 & AG & 311 & 254 & 300.2 & 94.6 & $2.7 \times 10^{-6}$ \\
rs2383206 & AG & 314 & 252 & 298.4 & 96.0 & $2.7 \times 10^{-6}$ \\
rs1333049 & CG & 324 & 399 & 347.7 & 100.2 & $3.8 \times 10^{-7}$ \\
\hline
\end{tabular}

${ }^{*} W=X+Y$ where $\mathrm{X}$ is the number of transmissions of the first-mentioned allele from heterozygote parents to affected siblings (TDT) and $\mathrm{Y}$ is the number of occurrences of the first-mentioned allele in affected sibs in remaining informative families (S-TDT).

The 3 SNPs are arranged in an order according to their positions in the chromosome 9. The risk alleles are G (rs10757274), G (rs2383206), and C (rs1333049).

eration and apoptosis) has not provided obvious candidate SNPs, which could explain the association with CHD $[4,5,16]$. Interestingly, a recent study showed that this region may be associated with type 2 diabetes [17]. It is anticipated that it could explain the coexistence of diabetes and CHD in some patients [18].

Compared to case-control studies, family-based studies have some unique advantages. Generally speaking, family members share a common genetic background. Moreover, they are more likely to have been exposed to similar environmental factors which could possibly be related to disease aetiology. The TDT/STDT test is also specially designed for complex diseases and, therefore, avoids the effects of confounding due to population stratification [12].

Larson and colleagues have recently reported the results of the Framingham Heart Study 100K project [19]. Using regression models with generalized estimating equations they did obtain a significant result for the chromosome 9 region but they failed to detect this when they used a family based association test (FBAT).

In our study, we have confirmed, using a familybased association approach, a significant association between SNPs in this region and CHD. The relative large numbers of informative families indicate the reliability of this study. The reported allele frequency for these 3 SNPs is similar in the Caucasian, Chinese and Japanese populations and very different from that found in the sub-Saharan African population [4,20]. The three chosen SNPs are in tight linkage disequilibrium (LD). Haplotype analysis provides more genetic information than analysis on a single locus. The haplotype analysis using the TRANSMIT program in our study also revealed a significant association between the GGC haplotype and early-onset CHD. This haplotype and its complementary haplotype (AAG) have frequencies of $56.3 \%$ and $39.7 \%$ in the White population (Hapmap data). Investigation of this region in other racial and ethnic groups will be helpful [21].

In summary, using a family-based study in an Irish population, we confirmed a strongly positive association between a region on chromosome 9p21.3 and early-onset CHD. This is the first family-based association study to demonstrate a significant association of this region with early-onset CHD. There are still a lot of unanswered questions concerning this region, which 
Table 4

Comparison of observed with expected haplotype transmissions to affected offspring for three common haplotypes $(>1 \%)$ obtained using the TRANSMIT program, which shows overtransmission of the GGC haplotype

\begin{tabular}{lccccc}
\hline Haplotype & Observed & Expected & Variance & Chi-square $(1 \mathrm{df})^{*}$ & $p$-value \\
\hline GGC & 685.8 & 634.7 & 107.0 & 24.4 & $7.9 \times 10^{-7}$ \\
AAG & 489.9 & 530.8 & 106.3 & 15.8 & $7.2 \times 10^{-5}$ \\
GGG & 22.2 & 30.3 & 11.6 & 5.71 & 0.017 \\
\hline
\end{tabular}

*df - degree of freedom.

Combined chi-square test $=26.4$ on $3 \mathrm{df}, P=7.9 \times 10^{-6}$.

Table 5

Frequencies of genotypes among 580 probands

\begin{tabular}{ccccccccc}
\hline \multicolumn{2}{c}{ rs 10757274} & \multicolumn{4}{c}{ rs2383206 } & \multicolumn{5}{c}{ rs1333049 } \\
\hline AA & AG & GG & AA & AG & GG & CC & CG & GG \\
110 & 262 & 208 & 103 & 260 & 217 & 204 & 257 & 119 \\
$(18.9 \%)$ & $(45.2 \%)$ & $(35.9 \%)$ & $(17.8 \%)$ & $(44.8 \%)$ & $(37.4 \%)$ & $(35.2 \%)$ & $(44.3 \%)$ & $(20.5 \%)$ \\
\hline
\end{tabular}

appears to be a gene-poor area of the genome. Further work focusing on this region using collaborative studies is required.

\section{Acknowledgement}

We thank the clinical staff for their valuable contribution to collection of families for this study. The research was supported by the Northern Ireland Research and Development Office, a Royal Victoria Hospital Research Fellowship, the Northern Ireland Chest, Heart and Stroke Association, and the Heart Trust Fund (Royal Victoria Hospital). The funding bodies were not involved in study design, the collection, analysis or interpretation of data, or in the writing of the manuscript for publication.

\section{References}

[1] M.E. Marenberg, N. Risch, L.F. Berkman, B. Floderus and U. de Faire, Genetic susceptibility to death from CHD in a study of twins, N Engl J Med 330 (1994), 1041-1046.

[2] S. Yusuf, S. Hawken, S. Ounpuu, T. Dans, A. Avezum, F. Lanas, M. McQueen, A. Budaj, P. Pais, J. Varigos and L. Lisheng and INTERHEART Study Investigators. Effect of potentially modifiable risk factors associated with myocardial infarction in 52 countries (the INTERHEART study): casecontrol study, Lancet 364 (2004), 937-952.

[3] T.M. Morgan, H.M. Krumholz, R.P. Lifton and J.A. Spertus, Nonvalidation of reported genetic risk factors for acute coronary syndrome in a large-scale replication study, JAMA 297 (2007), 1551-1561.

[4] R. McPherson, A. Pertsemlidis, N. Kavaslar, A. Stewart, R. Roberts, D.R. Cox, D.A. Hinds, L.A. Pennacchio, A. TybjaergHansen, A.R. Folsom, E. Boerwinkle, H.H. Hobbs and J.C. Cohen. A common allele on chromosome 9 associated with coronary heart disease, Science 316 (2007), 1488-1491.
[5] A. Helgadottir, G. Thorleifsson, A. Manolescu, S. Gretarsdottir, T. Blondal, A. Jonasdottir, A. Jonasdottir, A. Sigurdsson, A. Baker, A. Palsson, G. Masson, D.F. Gudbjartsson, K.P. Magnusson, K. Andersen, A.I. Levey, V.M. Backman, S. Matthiasdottir, T. Jonsdottir, S. Palsson, H. Einarsdottir, S. Gunnarsdottir, A. Gylfason, V. Vaccarino, W.C. Hooper, M.P. Reilly, C.B. Granger, H. Austin, D.J. Rader, S.H. Shah, A.A. Quyyumi, J.R. Gulcher, G. Thorgeirsson, U. Thorsteinsdottir, A. Kong and K. Stefansson, A common variant on chromosome 9p21 affects the risk of myocardial infarction, Science 316 (2007), 1491-1493.

[6] The Wellcome Trust Case Control Consortium, Genome-wide association study of 14,000 cases of 7 common diseases and 3,000 shared controls, Nature 447 (2007), 661-678.

[7] N.J. Samani, J. Erdmann, A.S. Hall, C. Hengstenberg, M. Mangino, B. Mayer, R.J. Dixon, T. Meitinger, P. Braund, H.E. Wichmann, J.H. Barrett, I.R. König, S.E. Stevens, S. Szymczak, D.A. Tregouet, M.M. Iles, F. Pahlke, H. Pollard, W. Lieb, F. Cambien, M. Fischer, W. Ouwehand, S. Blankenberg, A.J. Balmforth, A Baessler, S.G. Ball, T.M. Strom, I. Braenne, C. Gieger, P. Deloukas, M.D. Tobin, A. Ziegler, J.R. Thompson and H. Schunkert, WTCCC and the Cardiogenics Consortium, Genomewide association analysis of coronary artery disease, N Engl J Med 357 (2007), 443-453.

[8] M.S. Spence, P.G. McGlinchey, C.C. Patterson, C. Belton, G. Murphy, D. McMaster, D.G. Fogarty, A.E. Evans and P.P. McKeown, Family-based investigation of the C677T polymorphism of the methylenetetrahydrofolate reductase gene in ischaemic heart disease, Atherosclerosis 165 (2002), 293-299.

[9] W. Meng, A.E. Hughes, C.C. Patterson, C. Belton, M.S. Kamaruddin, P.G. Horan, F. Kee and P.P. McKeown, Genetic variants of Complement factor $\mathrm{H}$ gene are not associated with premature coronary heart disease: a family-based study in the Irish population, BMC Medical Genetics 8 (2007), 62 (doi:10.1186/1471-2350-8-62).

[10] G.A. Rose, H. Blackburn, R.F. Gillum and R.J. Prineas, World Health Organization: Cardiovascular Survey Methods. 2nd edition. Geneva: World Health Organization, 1982:178.

[11] H. Blackburn, A. Keys, E. Simonson, P. Rautaharju and S. Punsar, The Electrocardiogram in Population Studies. A classification system, Circulation 21 (1960), 1160-1175.

[12] R.S. Spielman and W.J. Ewens, A sibship test for linkage in the 
presence of association: the sib transmission/disequilibrium test, Am J Hum Genet 62 (1998), 450-458.

[13] Spielman lab: TDT \& S-TDT [http://genomics.med.upenn. edu/spielman/TDT.htm]

[14] D. Clayton, A generalization of the transmission/disequilibrium test for uncertain haplotype transmission, Am J Hum Genet 65 (1999), 1170-1177.

[15] University of Cambridge Institute for Medical Research. http:// www-gene.cimr.cam.ac.uk/clayton/software/transmit.txt

[16] W.Y. Kim and N.E. Sharpless, The Regulation of INK4/ARF in Cancer and Aging, Cell 127 (2006), 265-275.

[17] L.J. Scott, K.L. Mohlke, L.L. Bonnycastle, C.J. Willer, Y Li, W.L. Duren, M.R. Erdos, H.M. Stringham, P.S. Chines, A.U. Jackson, L. Prokunina-Olsson, C.J. Ding, A.J. Swift, N. Narisu, T. Hu, R. Pruim, R. Xiao, X.Y. Li, K.N. Conneely, N.L. Riebow, A.G. Sprau, M. Tong, P.P. White, K.N. Hetrick, M.W. Barnhart, C.W. Bark, J.L. Goldstein, L. Watkins, F. Xiang, J. Saramies, T.A. Buchanan, R.M. Watanabe, T.T.
Valle, L. Kinnunen, G.R. Abecasis, E.W. Pugh, K.F. Doheny, R.N. Bergman, J. Tuomilehto, F.S. Collins and M. Boehnke, A genome-wide association study of type 2 diabetes in Finns detects multiple susceptibility variants, Science 316 (2007), 1341-1345.

[18] J. Couzin and J. Kaiser, Genome-wide association. Closing the net on common disease genes, Science 316 (2007), 820-822.

[19] M.G. Larson, L.D. Atwood, E.J. Benjamin, L.A. Cupples, R.B. D’Agostino Sr, C.S. Fox, D.R. Govindaraju, C.Y. Guo, N.L. Heard-Costa, S.J. Hwang, J.M. Murabito, C. NewtonCheh, C.J. O'Donnell, S. Seshadri, R.S. Vasan, T.J. Wang, P.A. Wolf and D. Levy, Framingham Heart Study 100K project: genome-wide associations for cardiovascular disease outcomes, BMC Medical Genetics 8 (2007) (Suppl 1), S5 (doi:10.1186/1471-2350-8-S1-S5).

[20] http://www.ncbi.nlm.nih.gov/SNP/snp_ref.cgi?rs=1333049

[21] A. Rosenzweig, Scanning the genome for coronary risk, $N$ Engl J Med 5 (2007), 497-499. 


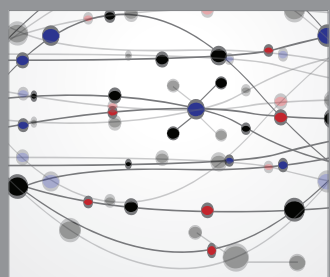

The Scientific World Journal
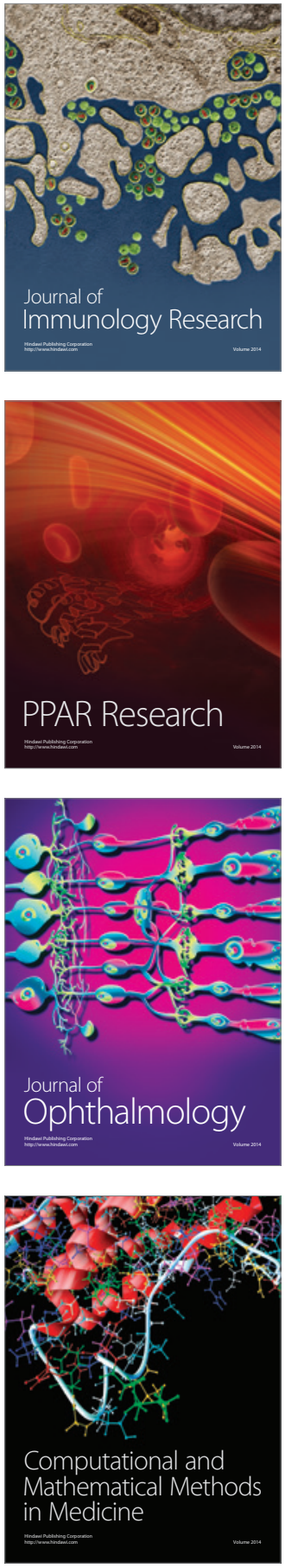

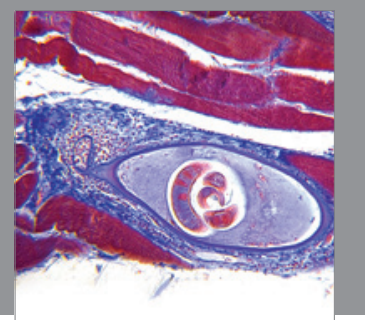

Gastroenterology

Research and Practice
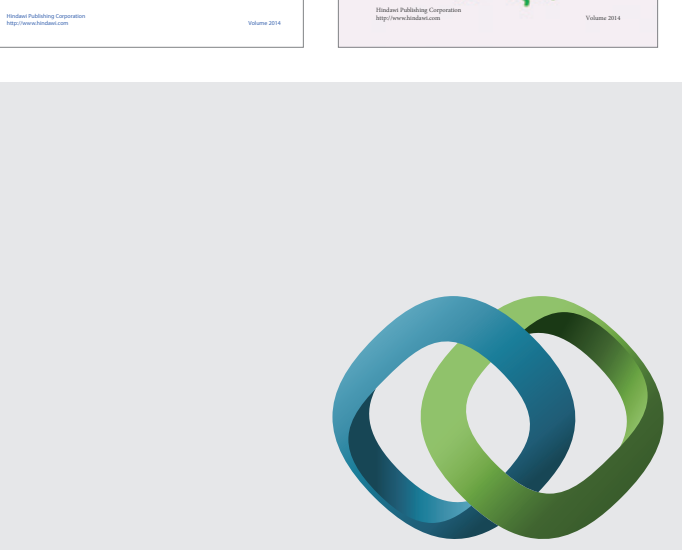

\section{Hindawi}

Submit your manuscripts at

http://www.hindawi.com
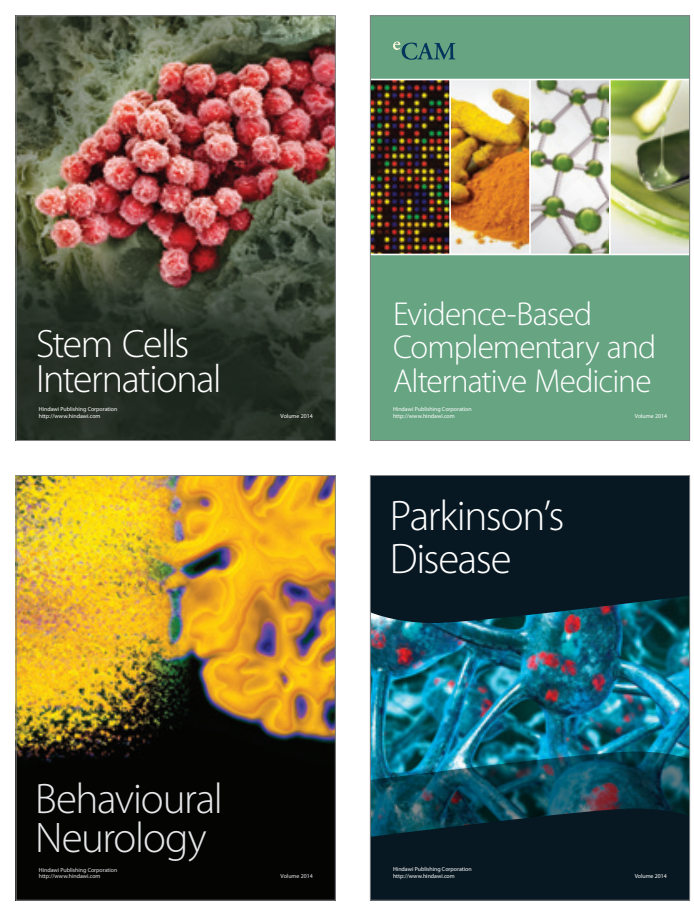

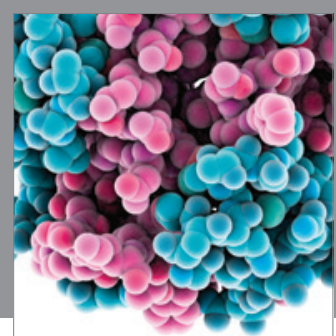

Journal of
Diabetes Research

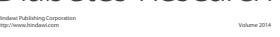

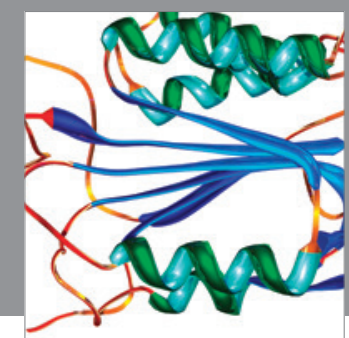

Disease Markers
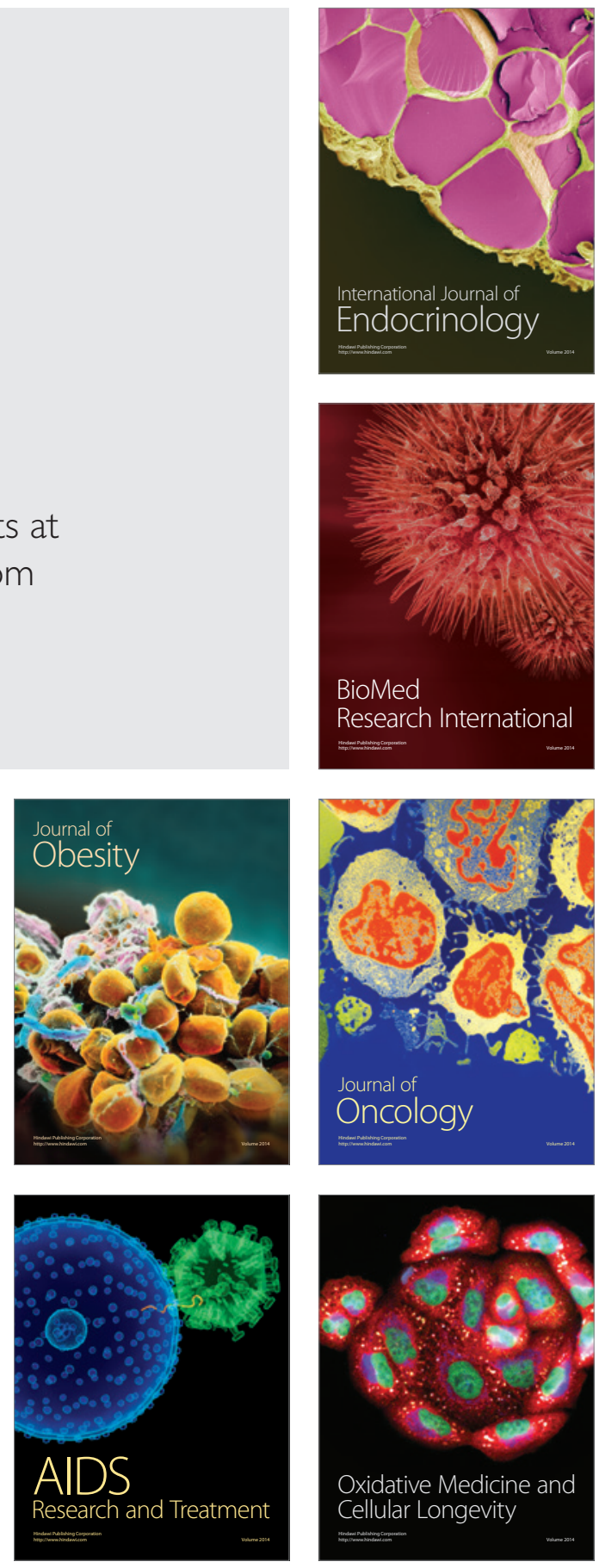